\title{
PREPARATION AND CHARACTERIZATION OF PEROVSKITE OXIDES BY POLYMERIZATION-COMBUSTION
}

\author{
J. A. GÓMEZ-CUASPUD ${ }^{1 *}$, J. S. VALENCIA-RÍOS ${ }^{1}$ AND J. B. CARDA-CASTELLÓ2 \\ ${ }^{1}$ Universidad Nacional de Colombia, Facultad de Ciencias, Departamento de Química, Laboratorio de Catálisis Heterogénea, Bogotá, D.C. Colombia. ${ }^{2}$ \\ Universitat Jaume I, Departamento de Química Inorgánica y Orgánica, Grupo de Química del Estado Sólido, Castelló de la Plana, España.
}

(Received: May 24, 2010 - Accepted: November 16, 2010)

\begin{abstract}
This paper describes the preparation of $\mathrm{La}_{0.75} \mathrm{Sr}_{0.25} \mathrm{Cr}_{0.2} \mathrm{Fe}_{0.8} \mathrm{O}_{3}$ perovskite oxide, using a polymerization-combustion route, to obtain materials for potential applications like electrodes in solid oxide fuel cells (SOFC). For such purpose, initially the solid precursor was characterized by FT-IR spectroscopy and thermal analysis (TGA-DTA), showing the obtention of polymeric citrate precursors. The thermal analysis (TGA-DTA), X-ray diffraction (XRD) and scanning electronic microscopy (SEM), provides information about the formation of a perovskite phase, while the texture, relief and roughness found are characteristic of the method of synthesis used. The size of crystallites, calculated using the Scherrer calculator software and transmission electron microscopy (TEM), confirmed the presence of nanometric crystallites $(<41.0 \mathrm{~nm})$, whereas the chemical composition and crystallographic structure, indicating a high correlation with respect to proposed system, which was confirmed by X-ray fluorescence (XRF), energy dispersive X-ray spectroscopy (EDS) and X-ray diffraction (XRD). Finally the electrical characterization by impedance spectroscopy (IS), determined the capacitance and resistance of the system in order to provide information related to the concentration of charge carriers and the diffusion rate of ions in the material a high conductivity values, related to semiconductor behavior for potential applications.
\end{abstract}

Keywords: anodes, citrate, coordination compounds, perovskite.

\section{INTRODUCTION}

The lanthanum and strontium chromite $\mathrm{La}_{0.75} \mathrm{Sr}_{0.25} \mathrm{Cr}_{0.2} \mathrm{Fe}_{0.8} \mathrm{O}_{3}$ system, is a ceramic material used as anode component in solid oxide fuel cells, due to its good conductivity in air and fuel-rich atmospheres, high stability and compatibility with other cell components [1]; additionally, it has to proved be a efficient catalyst in the combustion of light hydrocarbons like methane and propane, among others [2, 3-6]. However, the associated problems with low surface areas, loss of composition by volatilization of chromium and strontium species due to the effect of prolonged times of calcination [7], has enabled the development of alternative synthesis methods at low temperatures, which facilitate the obtention of materials that preserving and improving most of its textural, morphological and electrical properties [8,9]. In this context, this paper describes the preparation of $\mathrm{La}_{075} \mathrm{Sr}_{025} \mathrm{Cr}_{02} \mathrm{Fe}_{08} \mathrm{O}_{3}$ system, through polymerization-combustion process that promotes the obtention of coordination compounds in aqueous medium, under controlled conditions of $\mathrm{pH}$ and temperature, which when exposed to temperatures above $250{ }^{\circ} \mathrm{C}$ and oxidizing atmospheres to propitiate a spontaneous combustion process for obtention of solid oxides, this fact, decrease the synthesis temperature and prevents the potential volatilization of species, facilitating the modulation in the final concentration of ceramic as well as the preservation of a series of surface and textural properties of high interest in the field of SOFC components.

\section{EXPERIMENTAL}

For synthesis of $\mathrm{La}_{0.75} \mathrm{Sr}_{0.25} \mathrm{Cr}_{0.2} \mathrm{Fe}_{0.8} \mathrm{O}_{3}$ oxide, we used the corresponding metal nitrates of $\mathrm{La}\left(\mathrm{NO}_{3}\right)_{3} \cdot 6 \mathrm{H}_{2} \mathrm{O} \% 99.9 \%, \mathrm{Sr}\left(\mathrm{NO}_{3}\right)_{2} 99.8 \%, \mathrm{Cr}\left(\mathrm{NO}_{3}\right)_{3} .9 \mathrm{H}_{2} \mathrm{O}$ $99.98 \%$ and $\mathrm{Fe}\left(\mathrm{NO}_{3}\right)_{3} .9 \mathrm{H}_{2} \mathrm{O} 99.98 \%$ Merck 1.00 M. Similarly, citric acid monohydrate $2.00 \mathrm{M}$ ( $99.99 \%$ from Merck) was used. The solutions of cations were measured in a glass reactor equipped with magnetic stirring $(150 \mathrm{rpm}$.), temperature control and reflux at $80^{\circ} \mathrm{C}$ for 4 hours. The order of addition of the precursors was: $\mathrm{Sr}, \mathrm{La}, \mathrm{Cr}$ and $\mathrm{Fe}$, established by its corresponding hydrolysis constants, so that the total amount of cations in the reaction mixture was 0.01 mol. Once added each one of the cations, we proceeded to add the solution of citric acid in a molar ratio 1.5:1 to propitiate the development of the respective coordination compounds. Thus, the final concentration of cations in solution was $0.150 \mathrm{M}$ for the lanthanum, $0.050 \mathrm{M}$ for strontium, $0.160 \mathrm{M}$ for iron, 0.040 $\mathrm{M}$ for chromium and $0.600 \mathrm{M}$ for citric acid. The mixture was kept under reflux for 4 hours and then to recover the solvent by heating to $120^{\circ} \mathrm{C}$, to obtain a viscous liquid which was treated at $250{ }^{\circ} \mathrm{C}$ to form a precursor solid foam, which, was treated in a platinum crucible at $700{ }^{\circ} \mathrm{C}$ for 30 minutes, using a ramp of $50{ }^{\circ} \mathrm{C}_{\text {hour }}{ }^{-1}$ in air atmosphere to remove carbon residues remaining on the stage of self-combustion at $300{ }^{\circ} \mathrm{C}[10]$.
The obtained foam precursor was analyzed using a Perkin-Elmer FTIR1000 spectrophotometer, to confirm the presence of citrate species. The results were analyzed comparing the absorbance spectrums obtained and reported in OMNIC32® software and SDBS (Spectral database for organic compounds) databases.

The relationship between weight change and heat exchange in function of temperature (TGA-DTA) was carried out simultaneously on a Mettler Toledo TG-APMS TGA/SDTA851e/LF/1600 equipment under conditions of air flow $50 \mathrm{~mL} \mathrm{~min}-1$, in a platinum crucible with a heating rate of $5^{\circ} \mathrm{C} \mathrm{min}^{-1}$ between $25-1000{ }^{\circ} \mathrm{C}$, to evaluate the optimum temperature for the consolidation of the crystalline phase.

The chemical composition and crystallographic structure of solid was determined by X-ray diffraction, on a PANalytical X'Pert PRO MPD diffractometer, equipped with Ultra fast $\mathrm{X}^{\prime}$ celerator detector and BraggBrentano configuration, using $\mathrm{Cu} \mathrm{K}$ radiation $(\lambda=1.54186 \AA)$ between 10 and $90^{\circ}$ with steps of $0.02^{\circ}$ and irradiations of 40.80 seconds per step. The measures were developed with a voltage of $40 \mathrm{kV}$ and a current of 20 $\mathrm{mA}$. The refinement, indexing and the simulation of the structures was done with Cellref3.0® and Rietveld ${ }^{\circledR}$ software, allowed to establish the chemical composition and crystallographic structure. The crystallite size estimation was done using the highest diffraction signals, using the Debye-Scherrer equation, taking the value of half peak width set by a Lorentzian function and using a constant of 0.89 as reference.

Analysis by scanning electron microscopy (SEM) was carried out in a LEO 440 microscope (Leica-Zeiss), equipped with an electron gun and a spectrometer that measures the energy dispersive X-ray. The images were obtained with a focus distance of 10-25 mm, an accelerating voltage of $20 \mathrm{kV}$ and a current of 100-200 pA, measurement time of 100 seconds and counting rate $1.2 \mathrm{kcps}$. The samples were placed on a sticker attached to a graphite holder and aluminum objects shaded with platinum to obtain a better contrast in images.

The transmission electron microscopy analysis was performed on a JEOL 2100 microscope equipped with a $\mathrm{LaB}_{6}$ thermoionic gun operated with accelerating voltage of $200 \mathrm{kV}$, equipped with a CCD image acquisition system. For the analysis of the samples, they are milled to obtain fine powders, which were sieved to 200 U.S. mesh standard and dispersed in a probe tube with $5.0 \mathrm{~mL}$ of acetone, each tube was placed in ultrasound for a period of 30 $\mathrm{min}$, after which an aliquot of $1.0 \mathrm{~mL}$ of the upper each tube and again diluted to $5.0 \mathrm{~mL}$ with acetone, leaving again on ultrasound for a period of $5 \mathrm{~min}$ more, 
and finally, each copper grid was added one drop of each tube and allowed to dry at $45^{\circ} \mathrm{C}$ for 1 hour.

The composition of the solid was evaluated by X-ray fluorescence in a sequential spectrometer of dispersive X-ray wavelength Bruker S4 Pioneer and energy dispersive X-ray diffraction (EDS), with the purpose of obtain a compositional information of the ceramic.

In order to provides useful information on physicochemical properties of the system, the IS technique allowed the characterization of the electrical properties and the evaluation of information related to microscopic characteristics of the ceramic material by means variable frequency data, which was obtained in a impedance analyzer Agilent $4294 \mathrm{~A}$ between $40 \mathrm{~Hz}$ to 13 $\mathrm{MHz}$ with an $\mathrm{AC}$ amplitude of 0,1 volts. For fixed-frequency measurement in the selected range, we used a QuadTech 1920 LCR Analyzer, obtaining Nyquist type impedance plots. For this, it was prepared a pellet of $0.060 \mathrm{~g}$ of finely ground solid, using isostatic pressure (vacuum) of $1.0 \mathrm{t}$, in a PerkinElmer ${ }^{\circledR}$ pelletizer for 60 seconds. The pellet thus obtained was polished using $\mathrm{SiC}$ abrasive paper 400 , in order to provide a uniform surface for electrode fixation process, adjusting the thickness of the pellet at $0.50 \mathrm{~mm}$. The faces of the tablets were coated using a ink platinum (Engelhart Clal product: Ink Platinum 6082), which was deposited by thermal treatment for 1 hour at $900^{\circ} \mathrm{C}$ using a heating ramp of $5^{\circ} \mathrm{C} \mathrm{min}^{-1}$ for provide an adequate contact area, finally, data from this analysis were corrected by the global geometry of the pellet and the reference cell.

\section{RESULTS AND DISCUSSION}

In the initial part of the synthesis process, the preparation and the nature of the precursors of $\mathrm{La}_{075} \mathrm{Sr}_{025} \mathrm{Cr}_{02} \mathrm{Fe}_{0.8} \mathrm{O}_{3}$ oxide is subject to the presence in the reaction medium of different species whose concentrations are a function of $\mathrm{pH}$, ligand concentration and ionic strength, among others. This modeling was performed using the Hydra-Medusa software [11], to evaluate the behavior of each cation in solution with the purpose of obtain a homogeneous reaction medium. Once regulated the best synthesis conditions, the resulting solution was subjected to different thermal treatments, to obtain the solid foam precursor, which served to carry out subsequent characterization analysis.

The infrared characterization of the $\mathrm{La}_{075} \mathrm{Sr}_{025} \mathrm{Cr}_{0.2} \mathrm{Fe}_{0.8} \mathrm{O}_{3}$ precursor, allowed us to determine by comparison between the obtained absorbance and reported spectra in OMNIC32 database software and the spectral database for organic compounds (SDBS), the formation of a citrate precursor. Figure 1 shows the FT-IR spectra with their corresponding absorption bands, indicating the formation of a polymeric citrate complex. So, the bands located at 3791 and $3413 \mathrm{~cm}^{-1}$, be associated with vibrational tension modes of O-H links of dimers intermolecularly bonded to hydroxyl groups, which can be moved slightly by the $\mathrm{NH}_{4} \mathrm{OH}$ addition effect to the reaction medium [12]. In the same region at $3163 \mathrm{~cm}^{-1}$, is clear a tension mode band associated with the $\mathrm{O}-\mathrm{H}$ bond in carboxylic acid dimers linked to hydrogen bridges, which contains information from the N-H bond in tension mode. The bands located at 2340 and $2360 \mathrm{~cm}^{-1}$, correspond to stretching modes associated with the presence of occluded $\mathrm{CO}_{2}$, in the material pores, derived of thermal treatment of precursor foam, while the band located around $1855 \mathrm{~cm}^{-1}$, can be identified with a secondary vibration and vibration tension of the $\mathrm{C}=\mathrm{O}$ bond.

The band at $1729 \mathrm{~cm}^{-1}$, corresponds to the tension mode of the $\mathrm{C}=\mathrm{O}$ bond in carboxylic acid dimers saturated, its intensity increases in proportion to the concentration of iron in the material, which is associated with increased $\mathrm{pH}$ of the system during the precursor consolidation. On the other hand, the signal located at $1591 \mathrm{~cm}^{-1}$, is associated with asymmetrical tension mode of a COO- unidentate coordination compound, which can eventually move to lower wave numbers are also related to the same vibrational mode [13]. The band at $1385 \mathrm{~cm}^{-1}$, correspond to the symmetric tension mode of COO- bond associated with bidentate coordination compounds, and likewise, may contain information related to the $\mathrm{NH}^{4+}$ functional group. Another band to be increased to lower amount of chromium in the precursor, is located at $1231 \mathrm{~cm}^{-1}$, which corresponds to the $\mathrm{C}-\mathrm{O}$ mode stress related to presence of a acetic acid esters $\left(\mathrm{CH}_{3} \mathrm{COOR}\right)$, which can form in the drying process of the citric acid foams. The signals corresponding to the band at 1078 and $896 \mathrm{~cm}^{-1}$, corresponding to the $\mathrm{C}-\mathrm{O}$ mode bond stress associated with acetals and unsaturated aliphatic primary alcohols, as well as bending out of plane $\mathrm{C}-\mathrm{H}$ bond, which are present in the precursor and may contain information about the $\mathrm{NH}_{4} \mathrm{OH}$ added in the process of adjusting the $\mathrm{pH}$ of the reaction medium. The bands located at low wave number at 843,667 and $410 \mathrm{~cm}^{-1}$, corresponding to the binding of different metal cations of $\mathrm{La}^{3+}, \mathrm{Sr}^{2+}, \mathrm{Cr}^{3+}$ and $\mathrm{Fe}^{3+}$ with $\mathrm{OH}$ groups and oxygen atoms, whose vibrational modes $\mathrm{v}(\mathrm{O}-\mathrm{M}-\mathrm{O})$ may be strengthened in terms of $\mathrm{pH}$, also suffered slight shifts to lower wavelengths. This confirms that the $\mathrm{pH}$ of the medium chosen for the synthesis of oxide favors the formation of dimeric species of carboxylic acids, and the establishment preferred bidentate coordination compounds by COO- group and strengthening M-O links [13] as show in Table 1.

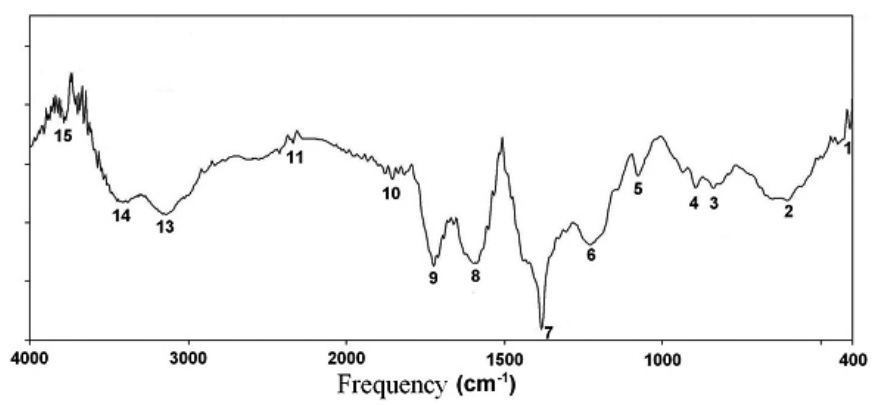

Figure 1.- Infrared spectrum of lanthanum and strontium chromite precursor in $\mathrm{KBr}$ pellet obtained at $25^{\circ} \mathrm{C}$, with its main absorption bands.

Table 1. The position of the infrared absorption band precursor, obtained through the OMNIC32 software and SDBS database.

\begin{tabular}{|c|c|c|c|}
\hline Band & Frequency $\left(\mathbf{c m}^{-1}\right)$ & Bond & Vibration mode \\
\hline 1 & 410 & M-O & Flexion $(m)$ \\
\hline 2 & 607 & M-O & Tension (antisimétrica $m)$ \\
\hline 3 & 843 & M-O & Tension (symmetrical $m$ ) \\
\hline 4 & 896 & C-O & Tension (symmetrical $m$ ) \\
\hline 5 & 1078 & C-O, C-H & Tension $(f)$ \\
\hline 6 & 1231 & -O & Tension $(f)$ \\
\hline 7 & 1385 & COO & Deformation $(m)$ \\
\hline 8 & 1591 & COO & Deformation $(v)$ \\
\hline 9 & 1729 & $\mathrm{C}=\mathrm{O}$ & Tension $(f)$ \\
\hline 10 & 1855 & $\mathrm{C}=\mathrm{O}$ & Secondary vibrations, tension $(f, 2$ bands) \\
\hline 11 & 2340 & $\mathrm{O}=\mathrm{C}=\mathrm{O}$ & Tension $(m)$ \\
\hline 12 & 2360 & $\mathrm{O}=\mathrm{C}=\mathrm{O}$ & Tension $(m)$ \\
\hline 13 & 3163 & $\mathrm{~N}-\mathrm{H} \mathrm{O}-\mathrm{H}$ & Tension $(m)$ \\
\hline 14 & 3413 & $\mathrm{O}-\mathrm{H}$ & Tension $(f$, wide) \\
\hline 15 & 3791 & $\mathrm{O}-\mathrm{H}$ & Tension $(f$, wide $)$ \\
\hline
\end{tabular}

Thermal analysis of precursor between 25 and $1000{ }^{\circ} \mathrm{C}$, revealed a slight increases in enthalpy associated with the evaporation of water retained by physical adsorption, additionally this stage demonstrated the presence of $\mathrm{OH}$ ligands, whose first stage of deprotonation occurs between 50 and $140{ }^{\circ} \mathrm{C}$ (zone I), which suggests differences in the mode of binding of water molecules, and end up between 150 and $200{ }^{\circ} \mathrm{C}$ (zone II) as indicated in Figure 2 .

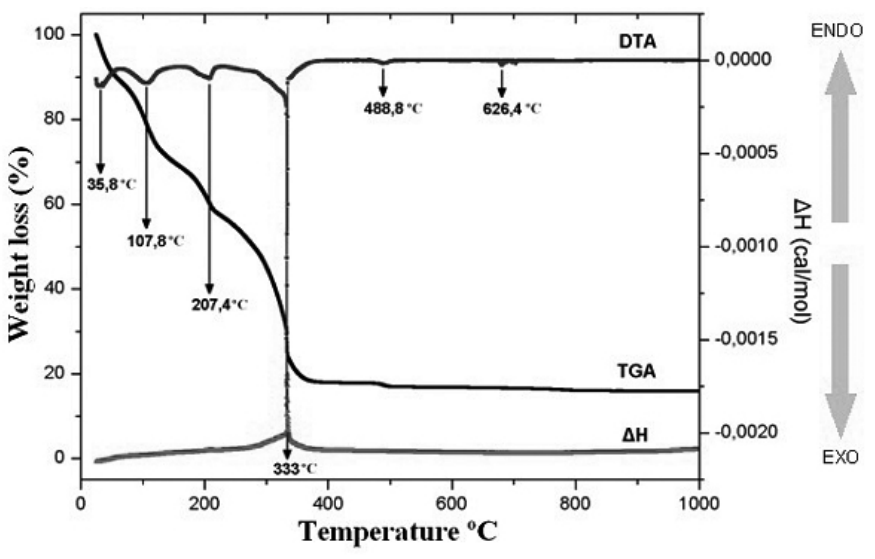

Figure 2. Thermal analysis (TGA-DTA) of $\mathrm{La}_{0.75} \mathrm{Sr}_{0.25} \mathrm{Cr}_{0.2} \mathrm{Fe}_{0.8} \mathrm{O}_{3}$ precursor. 
Dehydration continues until $210{ }^{\circ} \mathrm{C}$ and additionally in the case of citrate precursor, starts the formation of $\mathrm{C}=\mathrm{C}$ double bonds, with partial conversion of citrate to aconitate while ammoniacal species formation begins to appear between 200 and $235^{\circ} \mathrm{C}$ (zone III), together with the elimination of R-O radical species, accompanied by an endothermic event until $280^{\circ} \mathrm{C}$. Then, the system reach a maximum level of exothermicity, related to the combustion of organic matter between 280 and $335^{\circ} \mathrm{C}$ (zone IV), and the weight loss over $80 \%$. At this point, when most of the organic matter is destroyed and the removal of organic carbonates formed during the process is complete, start the consolidation of the oxide compound. The nature of the compounds that persist in this stage have been discussed in the literature $[14,15]$ and according to different reports, is clear the formation of carbonate species, and other intermediate oxo-carbonates formed in the synthesis process (zone V) [16,17]. Slight variations of mass that appear in IV and $\mathrm{V}$ zones at 488 and $626^{\circ} \mathrm{C}$, respectively, corresponding to decomposition of secondary species and solid oxide reorganization (Figure 2). Consequently, the analysis allowed us to find an ideal temperature calcination, which not only facilitated the obtention of $\mathrm{La}_{075} \mathrm{Sr}_{0.25} \mathrm{Cr}_{0.2} \mathrm{Fe}_{0.8} \mathrm{O}_{3}$ system, also avoids the possible volatilization of chromium species.

Further analysis by $\mathrm{X}$-ray diffraction, indicates that the $\mathrm{La}_{0.75} \mathrm{Sr}_{0.25} \mathrm{Cr}_{0.2} \mathrm{Fe}_{0.8} \mathrm{O}_{3}$ system has an adequate chemical composition and crystallographic structure, indicating a high correlation with respect to proposed system, with a preferential crystal orientation in the (011) plane, as shown in Figure 3. The crystallite size estimation was done using the highest diffraction signals, by Debye-Scherrer equation, taking the value of half peak width ( $\beta$ ), adjusted to a Lorentzian function and using a constant of 0.89 as reference, resulting in an average crystallite size of $39.0 \mathrm{~nm}$. The tolerance factor structure of the composition studied, was determined by the SPuDS software (Structure Prediction Diagnostic Software) [18], suggesting the stabilization of a perovskite structure. The search performed by the program X'Pert ${ }^{\circledR}$ High Score in ICCD databases indicates a classification according to the $\mathrm{La}_{0,8} \mathrm{Sr}_{02} \mathrm{FeO}_{3}$ reference oxide, JCPDS 00-035-1480, space group Pbn (62) orthorhombic crystal system with cell parameters $a=5.532 \AA, b=5.553 \AA, c$ $=7.835 \AA$ and cell volume $240.68 \AA^{3}$.

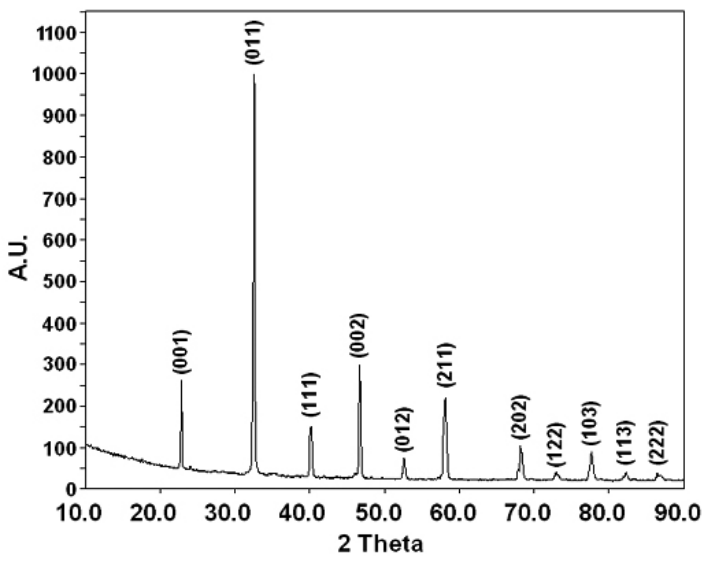

Figure 3.- X-ray pattern of $\mathrm{La}_{0.75} \mathrm{Sr}_{0.25} \mathrm{Cr}_{0.2} \mathrm{Fe}_{0.8} \mathrm{O}_{3}$ powder sample, obtained by the method of polymerization-combustion.

The subsequent refinement and indexing was done through Cellref3.0® software under the parameters mentioned above, using the 8 intensity highest signals, verifying that there are differences in about $0.045 \AA$, in terms of standard deviation for each indexed line with respect to those shown by the reference compound, which is explained by distortion that can generate the iron cation in the structure of chromite, situation that can be observed when comparing the unit cells of crystalline systems $\mathrm{La}_{0.75} \mathrm{Sr}_{0.25} \mathrm{Cr}_{0.2} \mathrm{Fe}_{0.8} \mathrm{O}_{3}$ and $\mathrm{La}_{0.8} \mathrm{Sr}_{0.2} \mathrm{FeO}_{3}$, calculated using the DiamondV3.1 software and the corresponding diffraction patterns as shown in Figure 4.
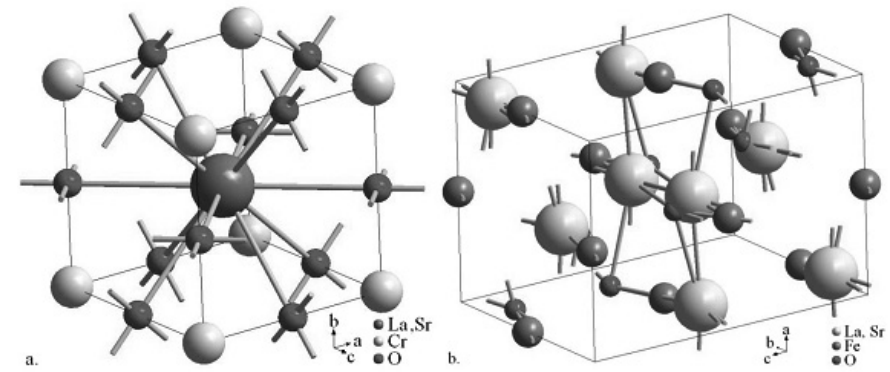

Figure 4.- Unitary cells of the $\mathrm{La}_{0.75} \mathrm{Sr}_{0.25} \mathrm{Cr}_{0.2} \mathrm{Fe}_{0.8} \mathrm{O}_{3}$ and $\mathrm{La}_{0.8} \mathrm{Sr}_{0.2} \mathrm{FeO}_{3}$ systems, calculated using the DiamondV3.1 software.

The $\mathrm{La}_{0.75} \mathrm{Sr}_{0.25} \mathrm{Cr}_{0.2} \mathrm{Fe}_{0.8} \mathrm{O}_{3}$ perovskite was studied by scanning electron microscopy, to analyze the different morphological and surface characteristics of particles; for that, the specimen was evaluated at different magnifications and some results are shown in Figure 7. From these micrographs it is clear that at the microscopic level, the solid is composed of irregular aggregates, distributed with particle sizes between 0.5 to $200 \mathrm{~mm}$ as shown in Figure 5. In principle, this picture is related to the texture and the relief created by the elimination of volatile substances that are produced in the combustion of organic compounds during thermal treatment (drying and calcination), also is notable that the obtained materials suffered some degree of densification, a fact that favored a compact morphology and it is reflected in the intensity of the (011) signal, but did not affect the size of the crystallites. The elemental analysis of the sample was studied by X-ray dispersive energy analysis, showing an adequate compositional profile, the results are discussed below along with those obtained by X-ray fluorescence.

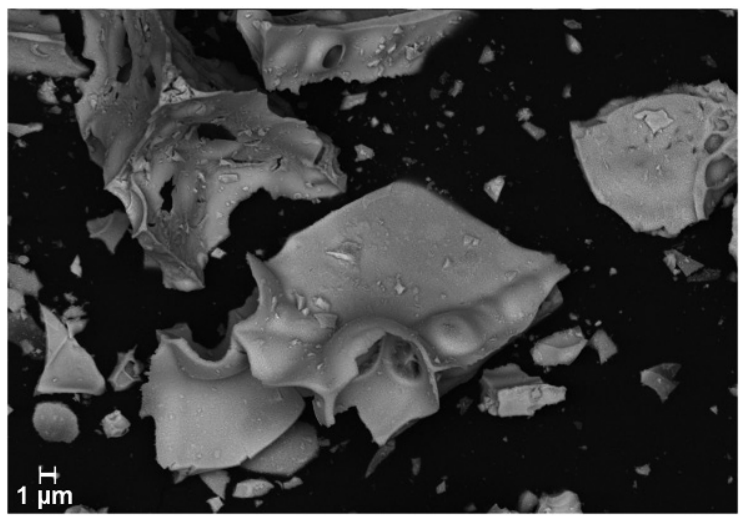

Figure 5.- Scanning electron micrographs for $\mathrm{La}_{0.75} \mathrm{Sr}_{0.25} \mathrm{Cr}_{0.2} \mathrm{Fe}_{0.8} \mathrm{O}_{3}$ sample.

The results of transmission electron microscopy, allowed us developing a statistical count in all micrographs obtained in a population of 300 particles, based on equation (1). Where $n_{i}$ is the number of particles and $d_{i}$ is the characteristic diameter of particle.

$$
d=\frac{\sum_{i} n_{i} d_{i}^{3}}{\sum_{i} n_{i} d_{i}^{2}}
$$

The data were normalized, confirming the presence of nanometric crystallites with regular morphology, and a average size of $41 \mathrm{~nm}$, crystallite outer areas of ca. $12,000 \mathrm{~nm}^{2}$ and interplanar distances of $0.32 \mathrm{~nm}$ for the (011) plane and grain boundary widths of at least $1 \mathrm{~nm}$ as shown in Figure 6. Similarly, the Figure 7 shows the histogram of particle size, which indicates that the distribution is unimodal with a strong Gaussian behavior. 


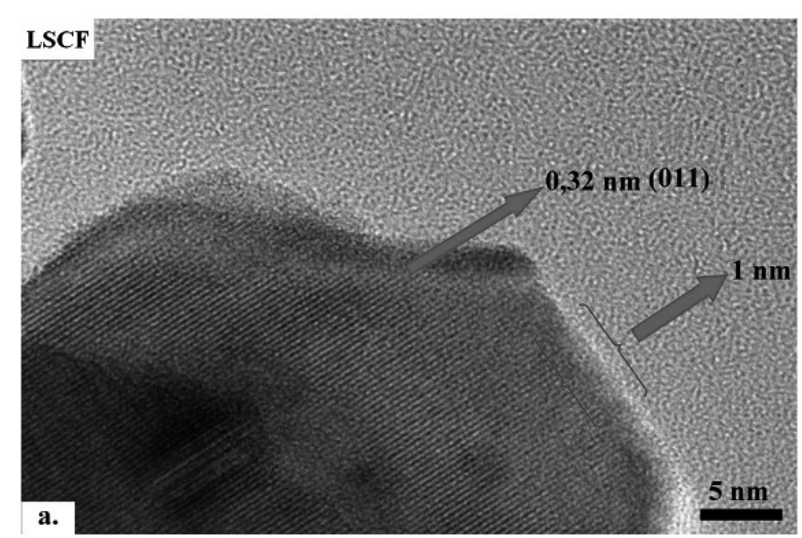

Figure 6.- Interplanar distances and grain boundary widths for the $\mathrm{La}_{0.75} \mathrm{Sr}_{0.25} \mathrm{Cr}_{0.2} \mathrm{Fe}_{0.8} \mathrm{O}_{3}$ system.

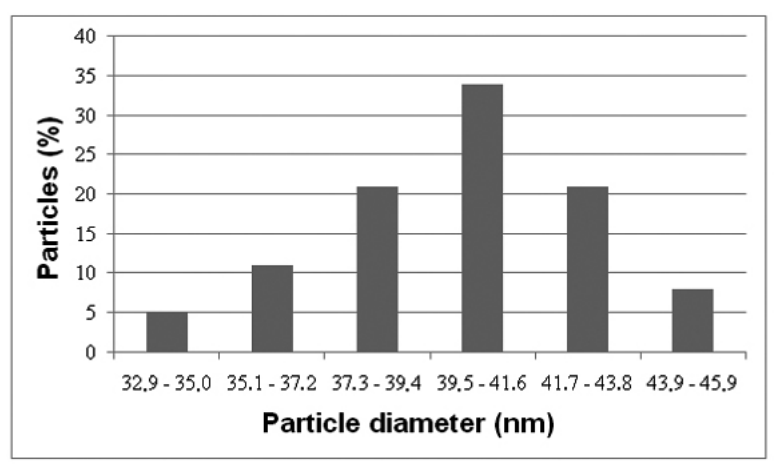

Figure 7.- Particle size distribution data determined from transmission electron microscopy.

The elemental analysis of the oxide, measured by XRF microanalysis and energy dispersive X-ray fluorescence, showed that the composition of the oxide is closely related to the expected values. These results are significant in the analysis of subsequent characterization tests, because provide information relating to the success of the synthesis in aqueous medium.

The analysis by impedance spectroscopy (IS), in order to evaluate the capacitance and resistance of the system in order to provide information related to the concentration of charge carriers and the diffusion rate of ions in the material, measured at $25{ }^{\circ} \mathrm{C}$ and displayed as Nyquist plot confirm that the solid have a semiconductor behavior with conductivities of $2.1 \times 10^{-3} \mathrm{ohm}^{-1} \mathrm{~cm}^{-1}$ as shown in table 2 .

Table 2.- Comparison of frequency values, resistance, capacitance and conductivity obtained at $25^{\circ} \mathrm{C}$ for $\mathrm{La}_{0.75} \mathrm{Sr}_{0.25} \mathrm{Cr}_{0.2} \mathrm{Fe}_{0.8} \mathrm{O}_{3}$ system, derived from the analysis by Zplot software.

\begin{tabular}{|c|c|c|c|c|c|}
\hline Component & $\begin{array}{c}\text { Frequency } \\
(\mathbf{H z}) \mathbf{x} 10^{6}\end{array}$ & $\begin{array}{c}\text { Resistance } \\
(\mathbf{o h m})\end{array}$ & $\begin{array}{c}\text { Capacitance } \\
(\text { Farads }) \\
\mathbf{x ~ 1 0} \mathbf{1 0}^{-10}\end{array}$ & Correlation & $\begin{array}{c}\text { Conductivity } \\
\left(\mathbf{o h m}^{-1} \mathbf{c m}^{-1}\right) \\
\mathbf{x ~ 1 0}^{-3}\end{array}$ \\
\hline LSCF & 3.7 & 471 & 4.6 & 0.997 & 2.1 \\
\hline
\end{tabular}

The detailed analysis of the results derived from Zplot software and showed at Table 2 indicates that the electrical behavior of solid is consistent with the desired characteristics for anodic materials, in which it is important to provide adequate levels of conductivity, with the purpose of allow reactant gases to diffuse to the electrolyte interface, since the oxidation reactions occur only in the three-phase boundary (TPB), where the gas phase, the metallic phase, and the anodic material are all in contact. The main results indicate that the oxide has high electrical conductivity, and the transport properties in this material are strongly dependent on the relative volume fraction of the phases, microstructure, and used calcination temperature. The behavior of resistivity, conductivity and capacitance, determine that both the capacitance as the permittivity are essentially independent of the frequency, it allows to perform a preliminary classification of material in the way of evaluating their behavior at higher temperatures. Based on these results, the sample was used to perform a study of impedance at $450^{\circ} \mathrm{C}$ to obtain the corresponding conductivity profile as a function of temperature as shown in Figure 8.

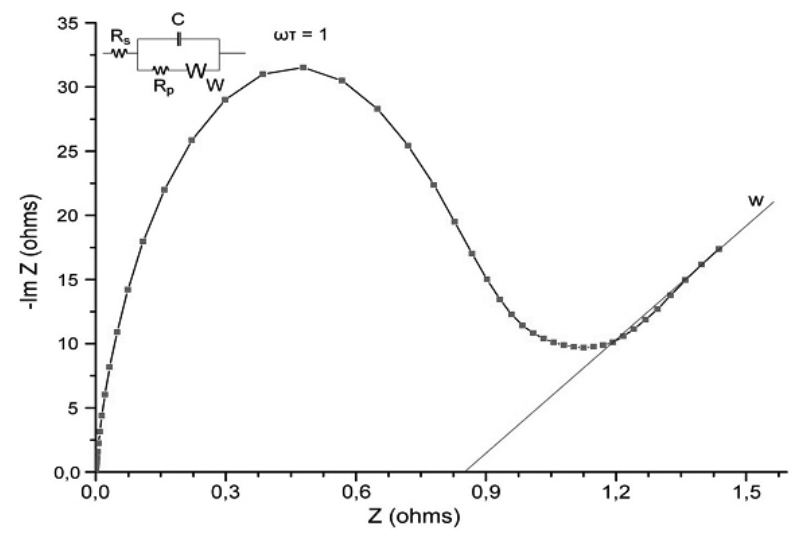

Figure 8.- Nyquist Plot of impedance, which represent the electrical behavior of the $\mathrm{La}_{0.75} \mathrm{Sr}_{0.25} \mathrm{Cr}_{0.2} \mathrm{Fe}_{0.8} \mathrm{O}_{3}$ system to $450^{\circ} \mathrm{C}$ with its corresponding equivalent circuit.

The equivalent circuit shown in Figure 8 indicates that a diffusional impedance related to charge transport phenomena in the material, functionally equivalent to a Warburg impedance, can arise at nonzero frequency. The element $R$, in Figure 8 represents the geometrical, or bulk resistance, while $C$, is the corresponding geometrical capacitance. Values for $R_{p}$, and $C$ and values of the equivalent circuit elements, can be estimated using the Zplot software. The representation of these results, together with that derived from that at room temperature, allowed to obtain the data in Table 3, where we can observe that the increase in temperature has a proportional effect in the conductivity of the $\mathrm{La}_{0.75} \mathrm{Sr}_{0.25} \mathrm{Cr}_{0.2} \mathrm{Fe}_{0.8} \mathrm{O}_{3}$ system in more of two magnitude orders.

Table 3.- Comparison of frequency values, resistance, capacitance and conductivity obtained at $450^{\circ} \mathrm{C}$ for the $\mathrm{La}_{0.75} \mathrm{Sr}_{0.25} \mathrm{Cr}_{0.2} \mathrm{Fe}_{0.8} \mathrm{O}_{3}$ sample derived from the analysis by Zplot software.

\begin{tabular}{|c|c|c|c|c|c|}
\hline Component & $\begin{array}{c}\text { Frequency } \\
(\mathbf{H z}) \times \mathbf{1 0}\end{array}$ & $\begin{array}{c}\text { Resistance } \\
(\mathbf{o h m})\end{array}$ & $\begin{array}{c}\text { Capacitance } \\
(\text { Farads }) \times \mathbf{1 0}^{-7}\end{array}$ & Correlation & $\begin{array}{c}\text { Conductivity } \\
\left(\mathbf{o h m s}^{-1} \mathbf{~ c m}^{-1}\right) \\
\mathbf{x ~ 1 0}^{-1}\end{array}$ \\
\hline LSCF & 2.1 & 1.3 & 3.7 & 0.999 & 7.6 \\
\hline
\end{tabular}

Under these conditions, it is clear that the level of conductivity obtained for $\mathrm{La}_{075} \mathrm{Sr}_{025} \mathrm{Cr}_{02} \mathrm{Fe}_{0.8} \mathrm{O}_{3}$ system, are strongly related with high electrical conduction levels similar to the state of the art of typical anodic materials as $\mathrm{Ni}$-YSZ, which confirm that it is possible to obtain polycationic perovskite materials, using the citric acid self-combustion method.

\section{CONCLUSIONS}

The main results indicate that the $\mathrm{La}_{075} \mathrm{Sr}_{025} \mathrm{Cr}_{02} \mathrm{Fe}_{08} \mathrm{O}_{3}$ oxide has high electrical conductivity, and that the transport properties in this material are strongly dependent of the relative volume fraction of the phases, microstructure, and temperature. These parameters should hence be taken into consideration for the optimized design of anodic materials. Additionally, it is clear that self-combustion method with citric acid is suitable for tuning the properties according to optimized parameters for specific applications.

\section{ACKNOWLEDGEMENTS}

This work was made possible through financial support of COLCIENCIAS, an organization that supports research and technological development in Colombia, through the project "Development of components for solid oxide fuel cells", code 110140520196 and 405/2007 notification.

\section{REFERENCES}

[1] S. C. Singhal, J. Electrochem. Soc. Proc., 16 (2001) 16. 
[2] G. Hoogers, Fuel Cell Technology Handbook, New York, Washington, 2003, p. 45.

[3] R. J. Gorte, J. M. Vohs, J. Catal., 216 (2003) 477.

[4] S. M. Plint, P. A. Connor, S. Tao, J. T. S. Irvine, J. Solid State Ionics., 177 (2006) 2005.

[5] N. Q. Minh, J. Am. Ceram. Soc., 76 (1993) 563.

[6] G. Pecchi, P. Reyes, R. Zamora, L. E. Cadús, B. P. Barbero, J. Chil. Chem. Soc., 51 (2006) 1001.

[7] M. Veith, S. Mathur, N. Lecerf, V. Huch, T. Decker, J. Sol-Gel Sci. Technol., 15 (2000) 145.

[8] F. Rioseco, L. Radovic, X. García, A. Gordon, G. Pecchi, J. Chil. Chem. Soc., 55 (2010) 44.

[9] L. Bouyssiéres, R. Schifferli, L. Urbina, P. Araya, J. M. Palacios, J. Chil. Chem. Soc., 50 (2005) 407.
[10] J. A. Gómez-Cuaspud, J. S. Valencia-Ríos, Rev. Col. Quim., 38 (2009) 289.

[11] I. Puigdomenech, Royal Institute of Technology. Stocholm, Sweden, 2002

[12] M. P. Pechini, U. S. Patent No. 3,330,697 11 July (1967)

[13] K. S. Weil, J. S. Hardy, J. Y. Kim, J. Adv. Mater., 2 (2007) 84.

[14] D. S. Todorovsky, M. M. Getsova, M. A. Vasileva, J. Mater. Sci., 37 (2002) 4029.

[15] M. M. Milanova, M. G. Arnaudov, M. M. Getsova, D. S. Todorovsky, J. Alloy. Comp., 264 (1998) 95.

[16] R. H. E. Van Doorn, A. Kruidhof, A. Nijmeijer, L. Winnubst, A. J. Burggraaf, J. Mater. Chem., 8 (1998) 2109.

[17] M. S. G. Baythoun, F. R. Sale, J. Mater. Sci., 17 (1982) 2757.

[18] M. W. Lufaso, P. M. Woodward, J. Acta Cryst. B., 57 (2003) 725. 